\title{
Database of extreme waves generated during the passage of a cold front in Rio Grande do Sul coast, southern Brazil.
}

Recebido: 27/10/2021 | Aceito: 06/12/2021 | Publicado: 20/12/2021 https://doi.org/10.53805/lads.v1i3.34

Dayanis M. Borges ${ }^{* 1}$, Humberto L. Varona², Marcelo F. Alonso ${ }^{1}$

\section{ABSTRACT}

This datapaper supports the use of a database generated from wavefield simulations with the WAVEWATCH III model in waters off the coast of Rio Grande do Sul in the South Atlantic Ocean. In the WAVEWATCH III simulations, three domains are generated as a part of a numerical experiment to set up the best configuration. This database includes all input and output files for the two best-fit simulations. Bathymetry and wind files at $10 \mathrm{~m}$ above the surface are available as input files. The period of simulation and non-stationary wind data input corresponds to March 22-28, 2016. The date was chosen because it is related to the passage of a cold front through the area of interest. The different parameterizations used and with which good results were obtained in the simulations with the model are also described. The WAVEWATCH III output files contain the spatial and temporal distribution of the wavefield in the area of interest, as well as the outputs for point locations consistent with the location of on-site records. For the two best-fit domains, the following variables were obtained: mean wind speed $\left(\mathrm{m} \mathrm{s}^{-1}\right)$, sea-air temperature difference $\left({ }^{\circ} \mathrm{C}\right)$, wave height $(\mathrm{m})$, mean wavelength $(\mathrm{m})$, mean wave period $(\mathrm{s})$, mean wave direction (degrees), mean directional propagation (degrees) and friction velocity $\left(\mathrm{m} \mathrm{s}^{-1}\right)$. All these variables are provided in NetCDF format and will serve as a reference for future wave modeling work in the region, and the results will be able to be compared with those obtained in the database.

Keywords: WAVEWATCH III model; GFS model; Total wave height; Peak wave period; Wind at $10 \mathrm{~m}$ above the surface.

\section{PRIOR PUBLICATIONS}

BORGES, D. M. Sistema de previsão de ondas oceânicas no litoral sul do Brasil e águas adjacentes do Oceano Atlântico Sul. 2019. Dissertação de Mestrado. Universidade Federal de Pelotas. Available at: <http://guaiaca.ufpel.edu.br:8080/handle/prefix/4567>.

\footnotetext{
${ }^{1}$ Federal University of Pelotas, Faculty of Meteorology, Pelotas-RS, Brazil. dayanis.borges@inpe.br.

${ }^{2}$ Federal University of Pernambuco, Department of Oceanography, Recife-PE, Brazil.
} 


\section{DATA IMPORTANCE}

- It serves as a reference for other wave modeling works, which will be allowed to compare their results with the results obtained in this database;

- It can be used for the analysis of physical processes linked to sea state and atmospheric conditions that occurred on the coast of Rio Grande do Sul during the simulation period, such as coastal flooding analysis. When high wave cores appear, it is possible to identify the main areas vulnerable to their arrival at the coast;

- It is an alternative to the problem of the scarcity of waveform records in the study area;

- In future works, this database can contribute to the creation of a wave monitoring system for the coast of Rio Grande do Sul based on the configurations used with the domains, bathymetries and parameterizations used.

\section{MATERIALS AND METHODS}

In the process of creating the wave dataset three domains of different sizes were defined (Fig. 1), the largest domain (WW3-1) includes the entire southern extent of the South Atlantic Ocean, from the west coast of South America to the coasts of the African continent. The boundaries of the WW3-1 domain are located at $70^{\circ} \mathrm{W}-25^{\circ} \mathrm{E} / 55^{\circ} \mathrm{S}-13^{\circ} \mathrm{S}$. The second domain
(WW3-2) spans from the west coast of South America to the vicinity of the coast of Africa and is located at $70^{\circ} \mathrm{W}-4^{\circ} \mathrm{W} / 55^{\circ} \mathrm{E}-13^{\circ} \mathrm{S}$. The smallest domain (WW3-3) spans from the east coast of South America to close to the middle of the South Atlantic Ocean and is located at $70^{\circ} \mathrm{W}-20^{\circ} \mathrm{W} /$ $55^{\circ} \mathrm{S}-13^{\circ} \mathrm{S}$. In the southwest of the Atlantic Ocean $\left(64^{\circ} \mathrm{W}-30^{\circ} \mathrm{W} / 45^{\circ} \mathrm{S}-21^{\circ} \mathrm{S}\right)$ is located the region of interest where wave simulations are made in deepwaters.

Figure 1. The Geographical locations of the WW3 domains used, the bathymetry of the region and the study region are located at $64^{\circ} \mathrm{SW}-30^{\circ} \mathrm{W} / 45^{\circ} \mathrm{S}-21^{\circ} \mathrm{S}$ (black line). The WW3-1 domain is the largest and is located at $70^{\circ} \mathrm{W}-25^{\circ} \mathrm{E} / 55^{\circ} \mathrm{S}-13^{\circ} \mathrm{S}$ (solid blue line), the WW3-2 domain located at $70^{\circ} \mathrm{W}-4^{\circ} \mathrm{W} / 55^{\circ} \mathrm{E}-13^{\circ} \mathrm{S}$ (dashed red line) and the WW3-3 domain located at $70^{\circ} \mathrm{W}-20^{\circ} \mathrm{W} / 55^{\circ} \mathrm{S}-$ $13^{\circ} \mathrm{S}$ (dotted pink line). Geographical locations of the model point outputs (Table 3) coinciding with the locations of the Rio Grande buoy (blue dot), the Santos buoy (red dot), the Tramandaí (Carmelite) and Cassino (green dot) ondographs.

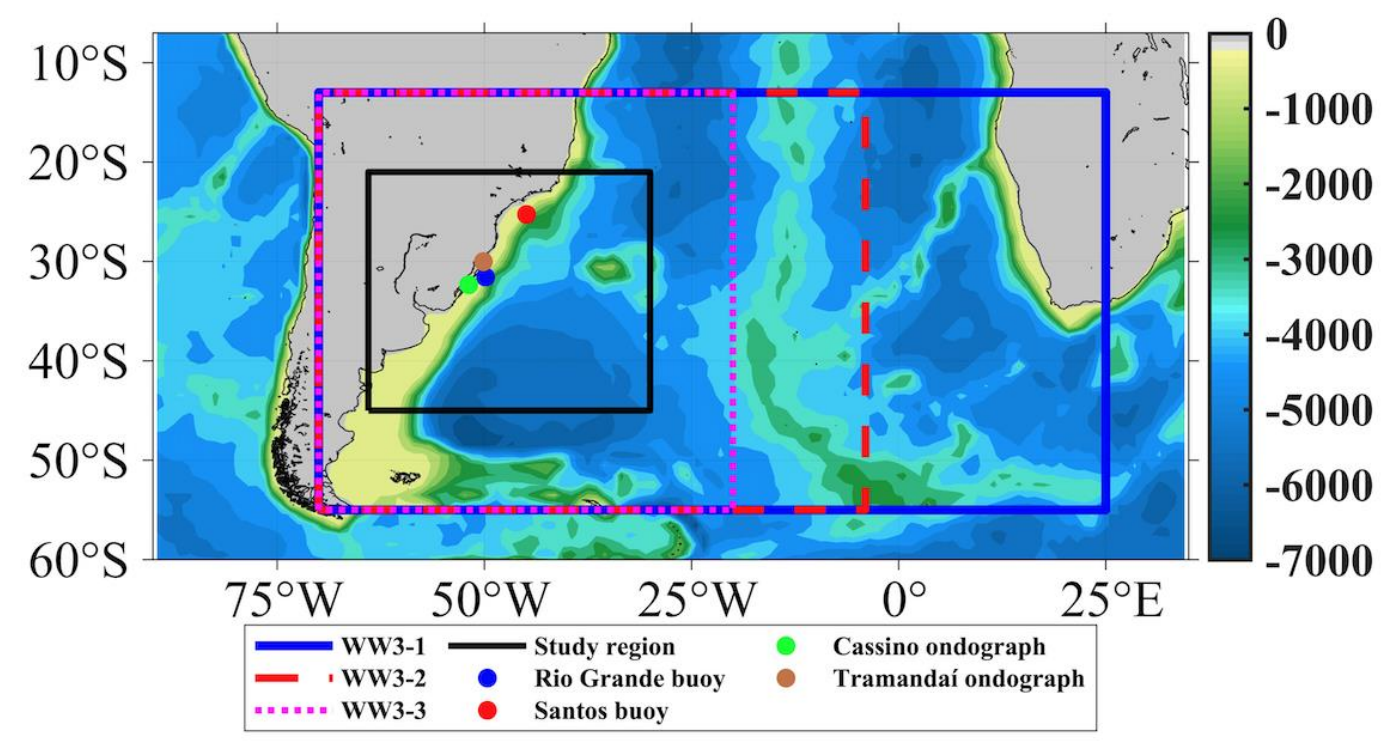

The simulation of the wavefield with the third generation WAVEWATCH III model (WW3) provided the wave parameters that are available in this dataset. For this numerical experiment, the 
input data were local bathymetry and nonstationary winds. The simulation period varies between March 22-28, 2016. 7 days in total. Three simulation domains (WW3-1, WW3-2 and WW33) were configured as a part of an experiment to establish the best simulation configuration for the area (Fig. 1). All simulation domains were defined with a region bigger than the study region to achieve a good representation of geographic fetch and thus a good representation of the propagation of swell arriving in the area. With this numerical experiment, a better representation of the simulated wave parameters is achieved and from it the best domain configurations are selected to have a lower computational cost without affecting the fetch, also avoiding the approximation to the boundary of the simulation domains to the study area, which introduces numerical dispersion errors with the wave model.

Table 1. Characteristics of the study area and WW3 domains considered in the preparation of the dataset in terms of geographic location and number of nodes in the grids.

\begin{tabular}{ccc}
\hline $\begin{array}{c}\text { Region } \\
\text { name }\end{array}$ & Geographical location & $\begin{array}{c}\text { Nodes } \\
\text { number }\end{array}$ \\
\hline $\begin{array}{c}\text { Study } \\
\text { region }\end{array}$ & $64^{\circ} \mathrm{W}-30^{\circ} \mathrm{W} / 45^{\circ} \mathrm{S}-21^{\circ} \mathrm{S}$ & - \\
WW3-1 & $70^{\circ} \mathrm{W}-25^{\circ} \mathrm{E} / 55^{\circ} \mathrm{S}-13^{\circ} \mathrm{S}$ & 64389 \\
& & $(381 \times 169)$ \\
WW3-2 & $70^{\circ} \mathrm{W}-4^{\circ} \mathrm{W} / 55^{\circ} \mathrm{S}-13^{\circ} \mathrm{S}$ & 50193 \\
& & $(297 \times 169)$ \\
WW3-3 & $70^{\circ} \mathrm{W}-20^{\circ} \mathrm{E} / 55^{\circ} \mathrm{S}-13^{\circ} \mathrm{S}$ & 33969 \\
& & $(201 \times 169)$ \\
\hline
\end{tabular}

\section{Initial and boundary conditions}

The freeware Gridgen v3.0 (NOAA) was used to generate the bathymetric grids. This program consists of a Matlab code set, two global highresolution bathymetric bases and a highresolution shoreline database (GSHHS - Global Self

- Consistent Hierarchical High-resolution Shoreline; WESSEL; SMITH, 1996). The bathymetric database used in these simulations was ETOPO1 (AMANTE; EAKINS, 2009) with $1 \mathrm{~min}$ of arc. As output of the Gridgen, 3 grids were obtained with the bathymetry information, the obstructions (used to define the contours of small islands that are not well represented due to the resolution of the bathymetry) and the mask (which has the information of the sea and the land). The wind data obtained from the reanalysis of the GFS model has a spatial resolution of $0.25^{\circ}$ and is available on the website https://rda.ucar.edu/datasets/ds084.1, this dataset includes the reanalysis and forecasts every 3 hours in the first 240 hours, then the interval is every 12 hours until the 384 hours of simulation. The GFS model is run four times a day at 00:00, 06:00, 12:00 and 18:00 UTC. The wind input files were created based on the wind components at $10 \mathrm{~m}$ above the surface at the 00:00 UTC reanalysis times of the GFS model, running at $00,06,12$ and 18 UTC. The Climate Data Operator (CDO) freeware created by Schulzweida (2006) was used to process the files in NETCDF format, select the area of the domains and extract the wind speed components at $10 \mathrm{~m}$ above the surface. All simulations were started 3 days before the dates of interest due to the spin-up and assumed a calm sea state.

\section{WW3 parameterizations}

The Tolman and Chalikov parameterization, later improved by Tolman and Chalikov(1996), defines the energy input source term (CHALIKOV; BELEVICH, 1993; CHALIKOV, 1995) and a new energy dissipation source term (TOLMAN; CHALIKOV, 1996). The parameterization considers the dissipation of high and low-frequency waves separately and potentially simplifies the effects of whitecapping within the wave energy balance (TOLMAN; CHALIKOV, 1994). The dissipation represents the idealized behavior of wave growth by limiting fetch, resulting in excellent growth in the case of short-range fetches. With the parameterization, smoother results of the simulated wavefield were obtained, and it is less sensitive to numerical errors (TOLMAN; CHALIKOV, 1996). Tolman 
(2002a) found that swell dissipation due to opposing or weak winds was severely overestimated and defined a filtered input source term to correct the problem. In a general way, swell formation, propagation and amortization are unraveled in detail (WW3DG, 2016).

Hasselmann et al. (1985) developed the most widely used parameterization to represent nonlinear interactions between waves (Discrete Interaction Approximation - DIA), the scheme calculates the nonlinear energy transfer between four-wave components (Quadruplets) in a gravitational wave spectrum. The scheme of Battjes and Janssen (1978) shows that the dissipation of wave breaking is reduced with depth. The objective parameterization extends the use of the model to shallow water environments where wave breaking becomes important. The JONSWAP spectrum of Hasselmann et al. (1973), is a simple parameterization representing wave energy loss due to friction with the bottom (WW3DG, 2016).

The wave propagation scheme used in the simulations was that of Tolman (2002b), which smoothes the wind diffusion effect, since it is known that with strong winds there is excessive deformation in the direction of wave propagation. The limited fetch JONSWAP spectrum (HASSELMANN et al., 1973) is the most suitable to represent the spectral approximation of waves in areas with lack of measurements, since the parameterization does not need data to be used The scheme calculates the local wave spectrum using the local wind direction and velocity, taking the dimension of the simulation domain as fetch. These parameterizations used were also used by Silva (2013) in Brazil.

\section{File formats and data access}

The dataset is composed by ascii, inp, nc, ctl and grads files extensions. The ascii and inp extensions are the simplest file formats in the database, and their content can be accessed from any text reader software. Another format used to available of the dataset is Grid Analysis and Display System (GrADS) format, which requires a GrADS descriptor file (clt file extension) to be read the data. These files can be accessed, manipulated and viewed with free GrADS software.

The Network Common Data Form (NetCDF) format is a set of software libraries and machineindependent data formats that support the creation, access and sharing of array-oriented scientific data. This format type does not need a data descriptor file as GrADS, it has all the information contained within your files (nc file extension). Among the main software used for NetCDF data manipulation are NetCDF visual browser (ncview), CDO, GrADS, Python and Matlab. GrADS and NetCDF formats are widely used by the earth science community so as meteorologists and oceanographers for their practicality in working with a large dataset. These formats types are characterized by multidimensional storage since they store data (variables) in 2D arrays (latitude $x$ longitude),3D arrays (latitude $x$ longitude $x$ time), and 4D arrays (latitude $x$ longitude $x$ time $x$ altitude).

\section{DATA DESCRIPTION}

A dataset contains files to simulate the extreme wave field during the passage of a cold front in southern Brazil with WW3 model. It also contains the output files of the simulation with WW3 model. The input files for the WW3 model are bathymetry and wind gridded data. The output type from the WW3 model were: 1) the spatial and temporal distribution of the wave field, and 2) point outputs from four locations coincident with the location of in situ records. It was also made available input files (ww3-2.inp and ww3-3.inp files) that show the parameterizations used in the two domain definitions of the WW3 model. All the files available in the dataset and their data type are shown in Table 2. Each of these files was generated for the WW3-2 and WW3-3 domains. Only the simulations for the WW3-2 and WW3-3 domains were available in the database 
since the WW3-1 domain had no differences in relation to the WW3-2 domain (BORGES, 2019).

Table 2. Files available in online dataset and data type contained.

\begin{tabular}{cc}
\hline Files & Type \\
\hline Bathymetry2.ascii, Bathymetry3.ascii & Bathymetry input \\
gfs-2.nc, gfs-3.nc & Wind input \\
ww3-2.inp, ww3-3.inp & Grid input \\
ww3-2.nc, ww3-3.nc & Spatial output \\
ww3-2.grads, ww3-3.grads & Spatial output \\
ww3-2.ctl, ww3-3.clt & Spatial output \\
ww3-2_tabs.tar.gz, ww3-3_tabs.tar.gz & Point output \\
\hline
\end{tabular}

\section{Dataset}

As input to the model, Bathymetry2.ascii and Bathymetry3.ascii files were generated with bathymetry data for the WW3-2 and WW3-3 domains, respectively, where water depth is in meters. Both files have a spatial resolution of approximately $27 \mathrm{~km}$ to match the wind resolution of the GFS model $\left(0.25^{\circ}\right)$. The wind data were entered as initial and boundary conditions in the WW3 model. The variables obtained from the GFS model were the zonal and meridional components of the wind at a height of $10 \mathrm{~m}$ above the surface in $\mathrm{m} \mathrm{s}^{-1}$ (Table 3). The wind input files are gfs-2.nc and gfs-3.nc for the WW3-2 and WW3-3 domains, respectively.

Table 3. Variables in wind files gfs-2.nc and gfs-3.nc and units of measurement.

\begin{tabular}{ccc}
\hline Description & Parameter name & Units \\
\hline U-Component of Wind & UGRD_10maboveground & $\mathrm{m} \mathrm{s}^{-1}$ \\
V-Component of Wind & VGRD_10maboveground & $\mathrm{m} \mathrm{s}^{-1}$ \\
\hline
\end{tabular}

Two types of outputs were generated from the WW3 model simulations for each domain: the spatial and temporal distribution of the wave field, and point outputs from four locations coincident with the location of in situ records. In NetCDF format are model outputs. The point locations belong to the geographical locations of the Rio Grande and Santos buoys, and the Tramandaí and Cassino ondographs (Table 4).

Table 4. Geographical location and types of stations used for validation of the simulations.

\begin{tabular}{cccc}
\hline Station name & Longitude & Latitude & Type station \\
\hline Rio Grande & $49.86^{\circ} \mathrm{W}$ & $31.53^{\circ} \mathrm{S}$ & Buoy \\
Santos & $44.92^{\circ} \mathrm{W}$ & $25.273^{\circ} \mathrm{S}$ & Buoy \\
Cassino & $51.90^{\circ} \mathrm{W}$ & $32.34^{\circ} \mathrm{S}$ & Ondograph \\
Tramandaí & $50.12 \mathrm{~W}$ & $30.01^{\circ} \mathrm{S}$ & Ondograph \\
\hline
\end{tabular}

The files generated with the spatial and temporal distribution of the wavefield were ww32.nc and ww3-3.nc for the WW3-2 and WW3-3 domains respectively. They contain the variables of the zonal and meridional components of the mean wind speed in $\mathrm{m} \mathrm{s}^{-1}$, the temperature difference between sea and air in degrees Celsius, wave height in $\mathrm{m}$, mean wavelength in $\mathrm{m}$, mean wave period in $\mathrm{s}$, mean wave direction in degrees, mean directional propagation in degrees, and friction velocity in $\mathrm{m} \mathrm{s}^{-1}$ (Table 5). Spatial and temporal wave field distribution outputs were 
also made available in GrADS format as an alternative model output format. The ww3-2.ctl and ww3-3.ctl files are the descriptors of the ww32.grads and ww3-3.grads data files for the WW3-2 and WW3-3 domains, respectively. The output variables for the GrADS files are described in Table 5.

Table 5. Variables simulated by WAVEWATCH III model (files ww3-2.nc and ww3-3.nc)and units of measurement.

\begin{tabular}{ccc}
\hline Description & Parameter name & Units \\
\hline Eastward wind & uwnd & $\mathrm{m} \mathrm{s}^{-1}$ \\
Northward wind & vwnd & $\mathrm{m} \mathrm{s}^{-1}$ \\
Air sea temperature difference & ast & $\mathrm{K}$ \\
Significant height of wind and swell waves & hs & $\mathrm{m}$ \\
Mean wave length & $\mathrm{Im}$ & $\mathrm{m}$ \\
Mean period & t01 & $\mathrm{s}$ \\
Direction media de waves & dir & degree \\
Wave mean direction & $\mathrm{spr}$ & degree \\
Eastward friction velocity & uust & $\mathrm{m} \mathrm{s}^{-1}$ \\
Northward friction velocity & vust & $\mathrm{m} \mathrm{s}^{-1}$ \\
Wave to ocean energy flux & foc & $\mathrm{W} \mathrm{m}^{-2}$ \\
\hline
\end{tabular}

In each domain ww3-2 and ww3-3 output tables were generated for four points, these output points coincide with the locations of the two buoys and the two ondographs (Table 4). Those outputs are contained in the compacted files ww3-2_tabs.tar.gz and ww3-3_tabs.tar.gz for the ww3-2 and ww3-3 domains, respectively. The compacted file ww3-2_tabs.tar.gz contains the outputs ww3-2BoyaRG_201603_tab.nc, ww32BoyaSanto_201603_tab.nc, ww32Cassino_201603_tab.nc and ww32Tramandaí_201603_tab.nc. On the other hand, the compacted file ww3-3_tabs.tar.gz contains the outputs ww3-3BoyaRG_201603_tab.nc, ww33BoyaSanto_201603_tab.nc, ww33Cassino_201603_tab.nc and ww33Tramandaí_201603_tab.nc. All these files contain the variables spectral estimate of significant wave height in $\mathrm{m}$, mean wavelength in $\mathrm{m}$, mean wave direction from spectral moments at spectral peak in degree, directional spread at spectral peak in degree, peak frequency in $\mathrm{s}^{-1}$, mean wave direction in degree and directional spread from spectral moments in degree (Table 6).

Table 6. Variables simulated by the WAVEWATCH III model at the points used for the validation of the simulations (files ww32BoyaRG_201603_tab.nc, ww3-2BoyaSanto_201603_tab.nc, ww3-2Cassino_20160603_tab.nc, ww3-2Tramandaí_20160603_tab.nc, ww3-3BoyaRG_20160603_tab.nc, ww3-3BoyaSanto_201603_tab.nc, ww3-3Cassino_20160603_tab.nc and ww33Tramandaí_20160603_tab.nc)and units of measurement.

\begin{tabular}{ccc}
\hline Description & Parameter name & Units \\
\hline Spectral estimate of significant wave height & $\mathrm{hs}$ & $\mathrm{m}$ \\
Mean wave length & $\mathrm{Lm}$ & $\mathrm{m}$ \\
Mean wave direction from spectral moments at spectral peak & Th1p & degree \\
Directional spread at spectral peak & Sth1p & degree \\
Peak frequency & $\mathrm{fp}$ & $\mathrm{s}^{-1}$ \\
Mean wave direction & th1m & degree \\
Directional spread from spectral moments & sth1m & degree
\end{tabular}




\section{SUPPLEMENTARY MATERIALS}

Data deposited in recognized open repositories

Dataset for the adjustment of a wave forecasting system for the deep waters of the South Atlantic Ocean and for the southern coast of Brazil. Numerical Wave Experiment in the South of Brazil (NWESB).

Repository name: Zenodo

DOI of the dataset: https://doi.org/10.5281/zenodo.5503845

Link to access the data: https://zenodo.org/record/5503845

Dataset for the adjustment of a wave forecasting system for the deep waters of the South Atlantic Ocean and for the southern coast of Brazil (Output files in GrADS format).

Repository name: figshare

DOI of the dataset: https://doi.org/10.6084/m9.figshare.16767058.v2

Link to access the data: https://bit.ly/3DO6GYU

\section{ACKNOWLEDGEMENTS}

D. M. B. thanks to Social Demand Program (DS) of the Coordenação de Aperfeiçoamento de Pessoal de Nivel Superior (CAPES) for the concession of master scholarships.

\section{REFERENCES}

AMANTE, C.; EAKINS, B. W. ETOPO1 1 Arc-Minute Global Relief Model: Procedures, Data Sources and Analysis, National Geophysical Data Center, NESDIS, NOAA, US Dept. Commerce, Boulder, CO, USA, 2008. DOI: https://doi.org/10.7289/V5C8276M.

BATTJES, J. A.; JANSSEN, J. M. Energy loss and set-up due to breaking of random waves. In: Conference on Coastal Engineering, 16, 1978, Hamburg. Coastal Engineering 1978. Reston: American Society of Civil Engineers, 569-587, 1978. DOI: https://doi.org/10.1061/9780872621909.034.

BORGES, D. M. Sistema de previsão de ondas oceânicas no litoral sul do Brasil e águas adjacentes do Oceano Atlântico Sul, 94p. (Dissertação de Mestrado em Meteorologia) Faculdade de Meteorologia, Universidade Federal de Pelotas, Pelotas. 2019. Available at <http://guaiaca.ufpel.edu.br:8080/handle/prefix/4567>. Accessed in 2021-06-13.

CHALIKOV, D. The parameterization of the wave boundary layer. Journal of physical oceanography, 25 (6), 1333-1349, 1995. DOI:https://doi.org/10.1175/1520-0485(1995)025<1333:TPOTWB>2.0.CO;2

CHALIKOV, D.; BELEVICH, M. Y. One-dimensional theory of the wave boundary layer. Boundary-Layer Meteorology, 63 (1), 65-96, 1993. DOI: https://doi.org/10.1007/BF00705377

HASSELMANN, K. et al. Measurements of wind wave growth and swell decay during the Joint North Sea Wave Project (JONSWAP). Ergaenzungsheft zur Deutschen Hydrographischen Zeitschrift, Reihe A, 8 (12), 95, 1973. Available at <https://pure.mpg.de/rest/items/item_3262854/component/file_3282032/content>. Accessed in 2021-09-02.

HASSELMANN, S. et al. Computations and Parameterizations of the Nonlinear Energy Transfer in a GravityWave Spectrum. Part II: Parameterizations of the Nonlinear Energy Transfer for Application in wave Models. Journal of Physical Oceanography, 15 (11), 1378-1391, 1985. DOI: https://doi.org/10.1175/15200485(1985)015<1378:CAPOTN>2.0.CO;2. 
SILVA, P. Caracterização do padrão de ondas na costa do Brasil por medio de modelagem numérica, 195p. (Dissertação de Mestrado em Meteorologia) Curso de Pós Graduação em Meteorologia, Instituto Nacional de Pesquisas Espaciais, São José dos Campos. 2013. Available at<http://mtcm16d.sid.inpe.br/col/sid.inpe.br/mtc-m19/2013/03.12.16.55/doc/publicacao.pdf>. Accessed in 2021-11-22.

SCHULZWEIDA, U. CDO user's guide. Hamburg: Climate data operators version 1.0.1. Max-Planck-Institute for Meteorology. $2006 . \quad$ Available at: <https://src.fedoraproject.org/lookaside/pkgs/cdo/cdo.pdf/90a93037089dddf6f8919b9d6c30bff7/cdo.pdf >. Accessed in 2021-09-30.

THE WAVEWATCH III DEVELOPMENT GROUP (WW3DG). User manual and system documentation of WAVEWATCH III version 5.16. Maryland: NOAA / NWS / NCEP / MMAB. Technical Note n. 329, 326p + Appendices. 2016. Available at <https://polar.ncep.noaa.gov/waves/wavewatch/manual.v5.16.pdf>. Accessed in 2021-06-17.

TOLMAN, H. L. Validation of WAVEWATCH III version 1.15 for a global domain. Washington DC: NOAA/NWS/NCEP/OMB. Technical Note n. 213. 2002a. Available at <https://polar.ncep.noaa.gov/mmab/papers/tn213/OMB_213.pdf>. Accessed in 2021-10-08.

TOLMAN, H. L. Alleviating the garden sprinkler effect in wind wave models. Ocean Modelling, 4 (3-4), 269289, 2002b. DOI: https://doi.org/10.1016/S1463-5003(02)00004-5.

TOLMAN, H. L.; CHALIKOV, D. V. Development of a third-generation ocean wave model at NOAA/NMC. In: Proceedings of the International Symposium: Waves-Physical and Numerical Modelling, 1994, Canada. World Meteorological Organizations-Publications-WMO TD. Vancouver: M. Isaacson and M. C. Quick, 725-732. 1994. Available at <https://polar.ncep.noaa.gov/mmab/papers/tn88/OPC88.pdf>. Accessed in 2021-07-25.

TOLMAN, H. L.; CHALIKOV, D. V. Source terms in a third-generation wind-wave model. Journal of Physical Oceanography, 26 (11),2497-2518, $1996 . \quad$ DOI: https://doi.org/10.1175/15200485(1996)026<2497:STIATG>2.0.CO;2.

WESSEL, P.; SMITH, W. A global, self-consistent, hierarchical, high-resolution shoreline database. Journal of Geophysical Research: Solid Earth, 101 (B4), 8741-8743, 1996. DOI: https://doi.org/10.1029/96JB00104. 